\title{
Improving continuity by simplifying the structure of family firms: a replication study
}

\author{
Angela Dettori ${ }^{1} \cdot$ Michela Floris $^{1}$ (D)
}

Received: 23 June 2021 / Accepted: 11 December 2021

(c) The Author(s), under exclusive licence to Springer Nature Switzerland AG 2021

\begin{abstract}
This study replicates a research undertaken in 2008 by Lambrecht and Lievens, Pruning the Family Tree: An Unexplored Path to Family Business Continuity and Family Harmony. Adopting an extended replication approach, this work analyzes a sample of family firms in Sardinia to investigate how and why family businesses prune the family tree to safeguard family harmony and business continuity. Our findings confirm that pruning is an effective strategy for managing complexity, increasing firm performance, and supporting succession plans. We extend the original study by stressing the relevance of pruning during succession.
\end{abstract}

Keywords Family business $\cdot$ Family tree pruning $\cdot$ Replication $\cdot$ Complexity management

\section{JEL Classification M190}

\section{Introduction}

Family businesses are generally defined as firms that are owned and actively managed by members of a family, and where "the business owner intends to pass the business on to other members of his or her family" (Astrachan and Shanker 2003, p. 212). Maintaining family control across generations, thereby involving an increasing number of family members in the firm's ownership, governance, and/or management, highlights the uniqueness of family firms, which generally intend to be managed by developing stability (Gimeno et al. 2010). However, it often has the disadvantage of the increasing firm and family complexity (Oudah et al. 2018; Qiu and Freel 2020; Gimeno et al. 2010). Sandig et al. (2006, p. 147) define family

Michela Floris

micfloris@unica.it

Angela Dettori

angela.dettori@unica.it

1 University of Cagliari, Cagliari, Italy 
complexity as "the number of family members and the kind of relationships established among them, the number of generations alive at a given point in time," and suggest that the greater the family complexity, the greater the differences among family members concerning interests, abilities, and ambitions. This introduces risks in managing family businesses, including succession, and needs different management and governance models according to their complexity profile (Gimeno et al. 2010).

Furthermore, as family firm complexity tends to increase over time, this causes changes in the ownership structure that often result in ownership dispersion and governance features modifications. In line with this assumption, family firm complexity needs governance-related changes (Gubitta and Gianecchini 2002). Many scholars proposed frameworks to capture how family involvement in ownership and governance tends to develop different typologies and categories of family firms. For example, Gersick et al. (1997) described three basic forms of family business ownership: controlling owner, sibling partnership, and cousin consortium, which identify an increasing ownership dispersion. Also, finding a decreasing extent of family involvement in the firm, and thus, a decreasing degree of familial norms' impact on the firm, Davis (2008) distinguished between family operator firms, family supervisor firms, and family investor firms.

Additionally, following Sharma and Nordqvist (2013), and building on the typologies of family businesses proposed by Gersick et al. (1997) and Davis (2008), Nordqvist et al. (2014) identified nine kinds of family businesses characterized by the different extent of family involvement in the business that requires appropriate governance bodies (from quite simple bodies as an advisory board and family meetings to more complex governance structures as the board of directors, Top Management Team, Shareholder's Assembly, and Family Council). Moreover, Gimeno et al. (2010) pointed out that according to the level of family and firm complexity, there are different typologies of family business models (the captain model; the emperor model; the family team model; the professional family model; the corporation model; the family investment group model). In other words, according to the extent of family and firm complexity, family firms have to develop specific structures to manage complexity. In another interesting study, González-Cruz and Cruz-Ros (2016) investigated three configurations of small-and-medium-sized family firms and highlighted the importance of adequate governance structures to ensure firms' survival and performance across generations managing the increasing complexity. More recently, Barontini and Bozzi (2018) proposed a categorization based on the generational stage (founder or descendants), the family representation (one or multiple family members) on the board, and the CEO type (family or professional). This non-exhaustive proposed review of relevant studies on family firm taxonomies resulting from complexity and its effects on management, governance, and ownership, underlines the importance that scholars recognize to the topic. When complexity is not adequately managed generally decreases managers' motivation (Schulze et al. 2003), successors' commitment (Gersick et al. 1997), and emotional attachment to the firm (Carney and Gedajlovic 2002), and it can translate into intrafamily conflicts (De Massis et al. 2013; Qiu and Freel 2020) and disagreement about 
leadership recognition and strategy definition, causing instability in firms during and after succession occurs (Campopiano et al. 2020a, b; Martin-Cruz et al. 2020).

Given this perspective, scholars have found that how a family exercises control, shares ownership, and assigns management responsibilities within the firm delineates family complexity and kinship ties, affects family members' emotional attachments, and impacts harmony and continuity in the firm (Fitz-Koch and Nordqvist 2017).

Intuitively, the greater the family complexity, the more complex management and continuity in the family business become. For this reason, family firms sometimes prune the family tree over time (Chen et al. 2021; Labaki 2007; Lambrecht and Lievens 2008; Suáre and Santana-Martín 2004; Westhead et al. 2002), defining a clear-cut distribution of ownership, governance, and management rights, and increasing engagement within younger generations of the family to avoid having passive family members involved in running the business (Chen et al. 2021). In other words, trimming the family tree appears to reduce family complexity, resulting in positive effects on the family firm's harmony and continuity.

Despite the relevance of this topic, given that family businesses often fail as a result of problems with managing family relations, settling family conflicts, and ensuring an equilibrium between the interests, goals, and expectations of the family and the firm (Großmann and Von Schlippe 2015; Memili et al. 2015; Schwass 2005), and the fact that several studies have addressed the effectiveness of pruning in avoiding passive owners and managing conflicts of interest among family owners (Basco 2013; Blanco-Mazagatos et al. 2016; Calabrò et al. 2017; Campopiano et al. 2020b; De Massis et al. 2013; Eddleston et al. 2008; Hoskisson et al. 2017; Sandig et al. 2006), to our knowledge only Lambrecht and Lievens (2008) have taken an empirical approach to evaluating the effect of pruning the family tree on harmony, longevity, and performance in family businesses by investigating how and why these businesses decide to prune their ownership and management ranks.

Driven by a desire to better understand the potential pruning offers with respect to managing family firm complexity and, thus, governing conflicts, ensuring family harmony, and supporting continuity within family firms, this study replicates the work in Lambrecht and Lievens (2008), adopting the same qualitative approach taken in that study while extending it to a sample of small and medium-sized family firms in Sardinia, Italy.

Our findings are largely consistent with those in the original study, reinforcing the relevance of pruning the family tree while introducing several novel elements. The most important new finding is the benefit of pruning during succession, underscoring the fact that trimming the family tree is an effective way to manage succession in a family firm that leads to rational and courageous decisions that are less characterized by the emotions that typically affect this crucial moment in the lifecycle of family businesses. Pruning makes it possible to manage current conflicts and prevent future ones after the incumbent's exit. 


\section{Family and business complexity in family businesses}

The nexus between family and business in family-owned businesses produces unique qualities that impact the challenges and issues family businesses face (Habbershon et al. 2003). It can be fertile ground for conflicts (Kellermanns and Eddleston 2004) because the family members that manage the firm are bound together by both co-ownership and, above all, family ties (Kotlar and De Massis 2013). Thus, family businesses appear to be characterized by a delicate relational equilibrium (Caputo et al. 2018). In transitioning from one generation to another, ownership, management, and governance change and evolve, usually increasing the level of business and family complexity (Sandig et al. 2006; Westhead et al. 2002). As shown in Sandig et al. (2006), family complexity can have negative repercussions for family members' satisfaction, sometimes destroying harmony in personal relationships and harming business performance. Multigenerational family firms can be particularly difficult to manage (Miller and Le Breton-Miller 2006) because family complexity translates into changes in ownership structure that lead to a progressive dispersion of shareholdings. In this situation, family cohesiveness declines due to differences in personal interests, values, and commitment to the business (Montemerlo 2005). In particular, Montemerlo (2005) holds that increased family complexity and, specifically, the growing number of family owners involved in the firm across generations, produces dispersed ownership that lacks cohesion, exacerbates differences in goals, increases agency costs (Gibb Dyer 2006; Schulze et al. 2003), constrains business growth and performance, and leads to a loss of entrepreneurial ability (Sandig et al. 2006), and emotional attachment (Siebels and zu Knyphausen-Aufseß 2012).

More recently, studies have found that ownership dispersion produces different kinds of family owners, namely active and passive, with diverse goals that create conflicts of interests (Basco 2013; Blanco-Mazagatos et al. 2016; Calabrò et al. 2017; Hoskisson et al. 2017). This can result in greater entrenchment on the part of the owner-managers who claim their power based on their ownership rights (Anderson et al. 2009). Passive and active owners generally differ in terms of risk propensity and perception (Hoskisson et al. 2017), time preferences, and use of profits (Witt 2008). Campopiano et al. (2020a, b, p. 769) argue that "the presence of passive family members in the ownership structure of the family firm is likely to lead to particular interests that alter the balance between socioemotional and financial motives characterizing family firms." Active owners in the family often attempt to exercise primary authority over key decisions, affecting the firm's strategy and sometimes leading the firm in a less risky direction (De Massis et al. 2013). In other words, family complexity affects family and business equilibria and, as complexity tends to increase across time, plays a role in a family business's growth (Brumana et al. 2017).

In this scenario, managing complexity becomes essential to ensure harmony and longevity across generations (Lambrecht and Lievens 2008; Simon et al. 2012). By doing so, family businesses can leverage more formal family relations 
and/or simplify management and/or ownership (Lambrecht and Lievens 2008; Montemerlo 2005) that can also prevent ownership dilution through succession (Klein et al. 2010). An equal distribution of shares has been shown to have negative effects (Santulli et al. 2019), while simplifying ownership and management translates into greater efficiency and a rational view of the family firm (Mukherjee et al. 2019). Investigating how and why family firms introduce simplicity is intriguing and in our view, calls for replicating the work done in Lambrecht and Lievens (2008).

\section{Background of the replication}

Lambrecht and Lievens (2008) view family tree pruning as an effective means of managing family firm complexity, and positively impacting firm longevity and family harmony by streamlining corporate governance and reducing conflicts between active and passive owners among family members. In their work, Lambrecht and Lievens (2008) focused on a sample of 17 Belgian family firms of varying size, in different industries, involving different generations and different areas of pruning (ownership, governance, and/or management).

Their findings underline the relevance of determining the right structure to manage the firms' potential level of complexity and indicate that not pruning in time can negatively affect business performance, increasing cost; for this reason, growth objectives for the family business are the main reason for reducing the number of family shareholders, thereby reducing conflicts among family owners. Moreover, despite several studies underline that pruning the family tree requires a significant amount of liquidity that, in turn, can interfere with the firm's growth, the authors found that business development and growth are engines to reduce the number of family shareholders. Additionally, their results highlight how pruning can help manage conflicts between family owners and non-shareowner's vision or noncommitted family members, opening the path to business growth. Rather than avoiding discussion about family owners reduction, the original findings demonstrate that pruning generally results in stronger family relations and in restoring family harmony. Another interesting conclusion is that pruning ensures good performance because the family business tends to assume the feature of the clan family firm, entailing that the remaining family owners and managers are generally the same individual or the shares are concentrated in a specific family branch. Finally, the third contribution is that there can be a positive relation between pruning the family tree and family business governance. Specifically, the authors found that family harmony resulting from family governance can facilitate the pruning that, in turn, can positively affect formal governance structure to manage complexity effectively. 


\section{Methodology}

As in the study we are replicating, our research question is why and how do family businesses prune the family tree?. Following Lambrecht and Lievens (2008), we adopt a multiple case approach to address the main research question and build theory (Eisenhardt and Graebner 2007; Yin 2008), because case studies are "essential for research into pruning the family tree" (Lambrecht and Lievens 2008, p. 299). Replication serves to validate the reliability of empirical research, determining whether the original results can be generalized by using a narrow or quasi-replication approach (Bergh et al. 2017; Bettis et al. 2016; Block and Kuckertz 2018; Singh et al. 2003). We adopt the quasi-replication perspective, following Singh et al.'s (2003) suggestions. Inspired by Weismeier-Sammer's (2011) extended replication, we intend to stay as close as possible to Lambrecht and Lievens's (2008) original study while adopting the good enough-principle, which holds that variations in social phenomena are to be expected and that precise duplication is impossible. For this reason, this study proposes a replication with minor extensions (Toncar and Munch 2010), intentionally modifying a few aspects of the original work.

\subsection{Research context}

Family businesses contribute 70\% of Europe's GDP (Caputo et al. 2018) and employ an enormous percentage of the workforce (Shepherd and Zacharakis 2000). Most are small to medium sized (EU 2020). In Italy, more than $85 \%$ of firms are familyowned, over $70 \%$ are small to medium sized, and $66 \%$ are fully managed by family members (EY 2017). In Sardinia, family businesses constitute $96 \%$ of the total and are generally both owned and managed by families (Crenos 2020). Given this, family business management is not only a concern for the firm itself; it is a community issue because it impacts the region's economy. The context of Sardinia is particularly attractive for investigating pruning in family businesses because a solid cultural heritage has been shown to have a notable impact on behavior in family firms (Kammerlander et al. 2015) and affects socio-economic development firmly rooted in culture and tradition (Dettori et al. 2020; Floris et al. 2020).

This replication analyzes a sample that differs from the original with respect to firm size (all are small and medium sized firms) and geographic context (Sardinia, instead of Belgium). The choice to limit size is primarily due to the fact that small and medium sized firms comprise the majority in Sardinia. Secondly, the focus on such firms is in line with the increasing attention of scholars and practitioners to this space because of small- to medium sized firms' worldwide capillary diffusion (EU 2020; OECD 2017). Finally, small and medium sized firms are often owned and managed by families, and such ownership is often associated with unique governance practices (Carney 2005).

The choice of a different context is based on suggestions of scholars who underscore the importance of contextualizing studies of family firms to deepen the 
understanding of their behaviors, performance, strategies, and decisions (Colli 2012; Sharma and Manikutty 2003; Zahra et al. 2014), and to connect local embeddedness to family business management, as belonging to a specific community is an essential factor in selecting a successor(s) (Baù et al. 2019).

\subsubsection{Cases selection and procedure}

Our replication adopts the same sample selection as the original study. We selected cases based on media articles and personal contacts established during seminars, lectures, and other meetings. Furthermore, after involving an initial group of CEOs of family firms in the study we asked them if they knew of other family firms that had experimented with pruning their ownership, management, and/or governance structure and identified additional cases through this snowball effect.

In defining the final sample (see Table 1), we determined the following criteria: Firms must (1) operate in the same region; (2) have more than one generation involved in running the business; and (3) have experience pruning in at least one of these areas: governance, ownership, and management. We intentionally chose firms in different sectors. To adhere as much as possible to the work done in Lambrecht and Lievens (2008), we studied 17 family firms.

As in the original work, case studies were carried out through in-depth, openended interviews (Eisenhardt and Graebner 2007). For each small family firm, we interviewed the family CEO as the knowledgeable agent actively involved in pruning (Gioia et al. 2013). Interviews were conducted using personal videoconferencing technologies (Skype and Zoom) (Bertrand and Bourdeau 2010; Deakin and Wakefield 2014; Iacono et al. 2016). Ethical practices were followed throughout the study, including documents signed to obtain formal consent.

\subsubsection{Data source and data analysis}

Following Lambrecht and Lievens (2008), we carried out within-case analyses, determining in each firm what its pruning entailed, why and how it was done, and the effects it generated. Each interview (average duration of $90 \mathrm{~min}$ ) was transcribed word for word and translated from Italian to English, resulting in a transcript of about 345 pages. We read the transcribed interviews several times and compared our data analyses and interpretations. After this first step, we continued to replicate the original study by proceeding to a cross-case analysis following Eisenhardt's suggestions (1989) - that is, by selecting categories and identifying within group similarities and intergroup differences. As in Lambrecht and Lievens (2008), to answer questions about the what, why, and how of pruning, we grouped our case studies by the area in which pruning occurred (ownership, governance, and/or management). 


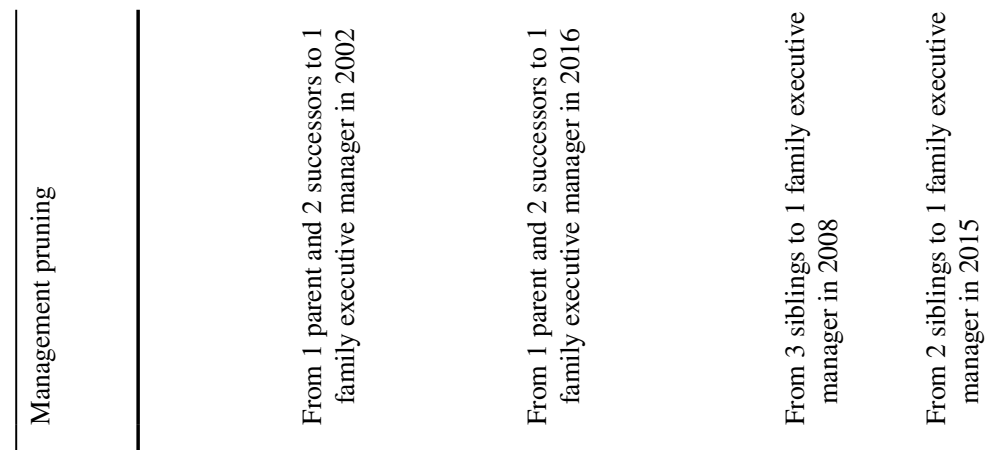

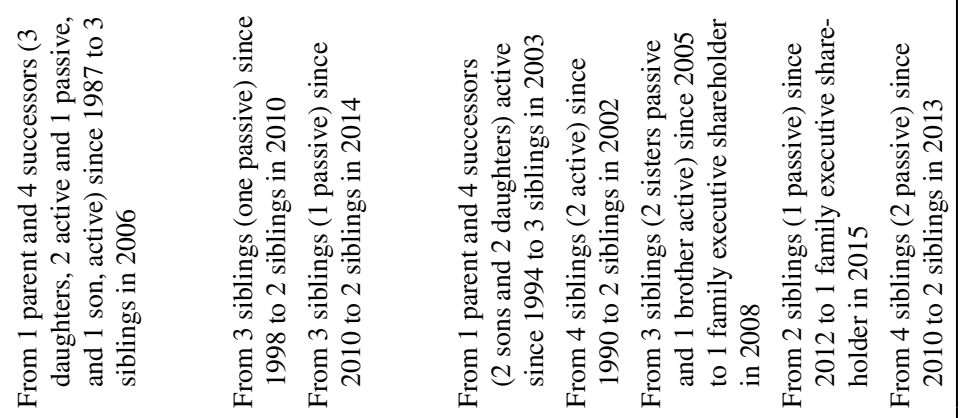

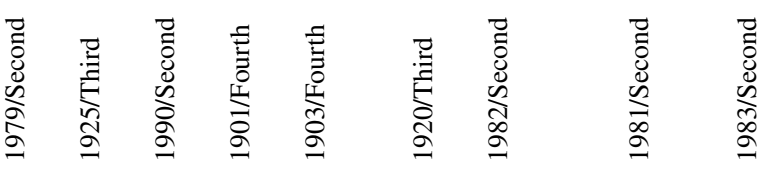

年

$+2$

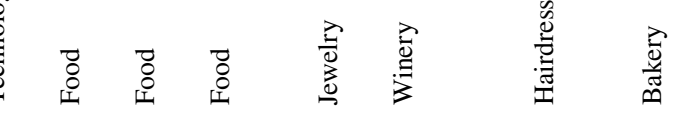

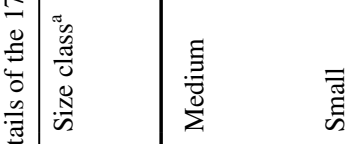

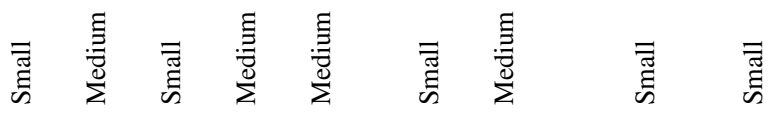

-

竞

N

n n 6

$\wedge \infty$ 


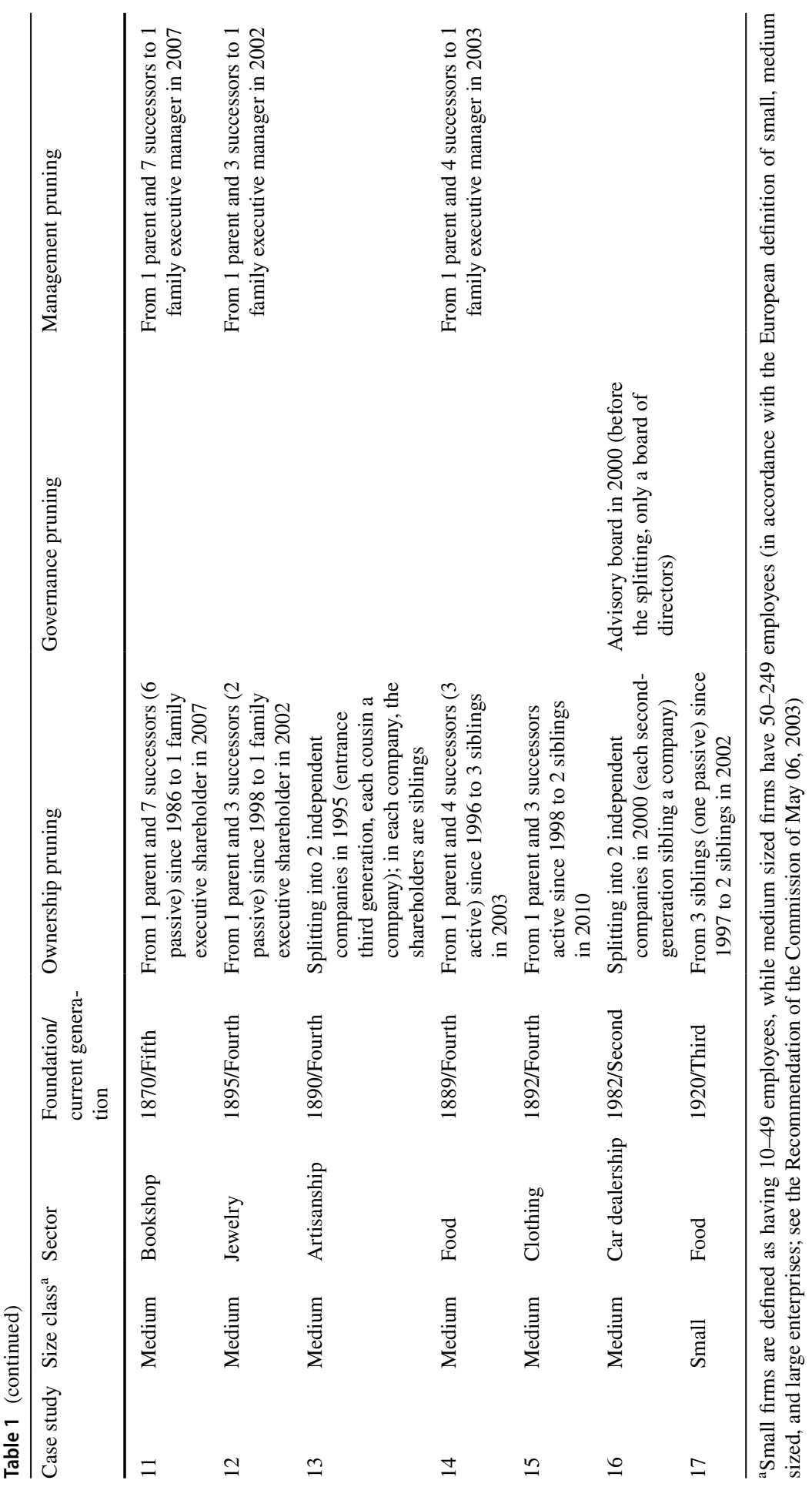




\section{Findings}

This section first explores what pruning the family tree implies, and then analyzes simplicity in ownership, governance, and management structures.

In contrast to the original study, in our sample pruning was done both for intragenerational and intergenerational simplification, assuming that pruning occurred during generational shifts (Lansberg 1999). In the light of this difference, we refer separately to Group A (Case studies 1, 2, 5, 6, 11, 12, 13, 14, 15) as those family firms that pruned during succession events, and to Group B (Case studies 3, 4, 7, 8, $9,10,16,17)$, as those that have pruned after succession took place.

\subsection{What does pruning the family tree entail?}

As in Lambrecht and Lievens (2008), our findings confirm that family tree pruning satisfies the two perspectives of simplicity. In 15 of our 17 case studies, pruning reduced the number of family owners and/or family managers. In Cases 13 and 16, the family businesses split into two independent family firms, leading to a more straightforward ownership structure.

\subsubsection{Group A}

Family firms that pruned during a succession event emphasized that the main reason of trimming was related to incumbents' intention to avoid potential conflicts, as illustrated by the following quote:

(...) our father has always planned everything, and for fear of leaving chaos and generating conflicts by his leaving the family business, he defined for each of us the roles that best suited our abilities. (Case 2)

In Cases $1,11,12$, incumbents decided to reduce the number of passive family member-owners, relegating them to operational roles as employees or suggesting that they sell their shares and leave the firm. This was due to a "(...) question of justice and correct distribution of roles based on the real participation in the company, regardless of blood relations" (Case 1). In Case 11, which deals with a business that was owned by eight family members (one representative of the older generation, one active son, and six passive siblings) when the pruning occurred, all shares were conferred to the active son while the passive siblings were placed in minor positions. The family manager who is still with the firm, reports:

My father witnessed many of our fights because each of us complained about the others' lack of commitment. Only I, to be honest, have invested all of myself in the family business. My father did one thing right: when the time came to formalize the generational change, he decided to give me all the shares. My brothers play other minor roles. (Case 11) 
The incumbents selected the successor(s) by focusing on "the future of the firm" (Case 1), mainly on the basis of "commitment, efforts, and competencies" (Case 14), and a "sense of belonging, and leadership attitudes" (Case 6). This rational approach emerges in more detail, in the following statement:

My father has always thought with his heart and acted with his mind. (...) also happened for succession matters. He planned the succession, imagining that his decisions would create discontent and perceptions of injustice among us successors, but he thought about the company's future. This is why he preferred that I become the sole owner. (Case 14).

Pruning often initially produces "disputes and misunderstandings among successors that threaten to destroy family harmony" (Case 11); however, the decision "proved to be the best for guaranteeing business continuity and family union" (Case 11). In this sense, pruning generated "several positive effects on firm management and family unity, thanks to a clearer firm structure, and a well-managed equilibrium between the firm and family interest." (Case 6). Only in Cases 5 and 14 did several conflicts emerge, as follows:

We have lived the dark side of pruning during our succession. It was a very courageous decision and the results tell us that the choice is right for our firm, but a little less so for the family's harmony. We have experienced dark times. (Case 14)

\subsubsection{Group B}

For the family firms in this group, the main reason was retrieved in the right definition of shares based on the real effort of each family members as the following quote explains:

After our father gave us the company, we decided to define the ownership shares around the useful contribution that each of us successors was making. (Case 10)

Here, the successors decided to prune because "after more than ten years spent in disputes, conflicts, and recriminations, we decided to change the ownership structure, allowing only those interested to take the company's reins." (Case 7).

As in the findings of the original study, our case studies confirm that simplifying the shareholding structure generally reduces the number of family shareholders, with positive effects for the firm and the family (except in Case 4, where the family experienced conflicts), as shown in the following statement:

Selecting family members for ownership shares to include only those who have always really worked well for the company was a success. (Case 8)

Furthermore, most of the case studies in this group show that the family tree prior to pruning included several active and passive family shareholders. In the original study, pruning did not involve trimming away the passive shareholders, while in 
our sample most firms removed passive family members from ownership or senior positions (Cases 3, 4, 7, 8, and 17) with the goal of "reducing conflicts of interests among successors and ensuring that only those committed in the firm can make decisions." (Case 7).

\subsection{Simplifying ownership structure by reducing the number of family shareholders}

Why? Introducing simplicity into the ownership structure mainly depends on the willingness of the family buyer who, according to Lambrecht and Lievens (2008, p. 305), is the one "who takes the lead to buy out family members." Simplifying occurs less frequently on the side of the family seller, defined by the authors as the one "who takes the initiative to sell his or her shares to other family members." Our case studies are partly aligned with those in the original study because, in addition to the intentions of family buyers and family sellers, the incumbent parent's desire to define the new ownership structure before leaving the firm emerged strongly, to spare the successors from having to settle disputes and family conflicts in the future.

\subsubsection{Group A}

In this group, the main reasons for pruning were dictated by the "need to ensure that only those successors really committed in the firm were given the power to make decisions" (Case 1), and "to prevent conflicts that would undoubtedly emerge among those who are interested in the firm growth and those who are pushed by self-interest." (Case 15).

Echoing the original study, another reason is related to the desire for family firms' continuity, as shown in the following:

My father has demonstrated courage by choosing me. He told me that the continuity of the firm was in my hands; thus, he decided to give me the entire property and the management rights. (Case 11)

Finally, also within this group we find that a sense of context identity and belonging represents a strong stimulus to prune, acting as a means of selecting among active and passive family owners. Active family owners appear to be interested in managing the firm for themselves, valorizing local traditions, and being legitimized through the context in which they live and operate. Passive family owners appear to be less engaged than their active counterparts, not perceiving the business as a mission to preserve and protect knowledge, skills, and centuries-old traditions to hand over to future generations.

My father has always said that ours is a mission: to tell, preserve, protect, and pass on the history of our land. Our jewels speak about and guard Sardinia, making it known overseas. (...) Every day, I strive to innovate our creations without ever forgetting our history, traditions, uses, and customs. (Case 12) 


\subsubsection{Group B}

As in Lambrecht and Lievens (2008), our findings reveal that the primary motivations for pruning are grounded in the achievement of personal goals in terms of business growth and long-term survival, as expressed in the following:

We decided to buy our sister's shares because she was not interested in our firm (...) We have experienced many conflicts about this with her but it was necessary to make the right choice for the firm's future. (Case 4)

My brother has never shown the same commitment as I have to the company, and he realized that he was not satisfied. So, he thought about selling his ownership stakes and collaborating with the company in other ways. (Case 9)

Most of our interviewees focused on the "need to have family owners who are committed to and engaged in the firm" (Case 3) to ensure growth and, simultaneously, achieve self-efficacy and increase self-esteem.

Cases 9 and 10 show that family sellers are also aware of the role of personal engagement in ensuring firm growth, as follows:

(...) My brother voluntarily sold his shares because he realized he didn't feel as committed to the firm. This situation was causing him frustration, but now that he is no longer formally owner he is much better off. (Case 10)

Our findings show another compelling reason for ownership pruning: attachment to the context in which the family firm operates and family members reside. The following statements explain this concept:

(...) Initially, all three of us were present. However, my younger sister wasn't interested (...). To do this job, you need to be attached to tradition, know our history, and express the intention to perpetuate the knowledge and flavors through time. (Case 4)

Our bread is the result of the sacrifices of many people: those who cultivate the traditional Sardinian durum wheat, those who collect it and those who grind it, and finally, us. (...) You have to love your land to appreciate such a tiring job. Two of us do not feel we have an active part of this effort. (Case 10)

Table 2 syntheses the concepts mentioned here.

How? In the original study and in all of our cases, before proceeding to simplify ownership of the family business, business consultants and experts were engaged to evaluate the firm, protect family relationships and family harmony, and minimize debate about the share price. This is done because, as explained by the following quote, all of the cases underscore the great difficulty of family owners evaluating their own firm:

The most serious difficulty was to assign a value to our company. For us it is such a great treasure, with such deep roots as to be of inestimable value. So, we consulted a professional who, objectively, defined a value. (Case 7) 


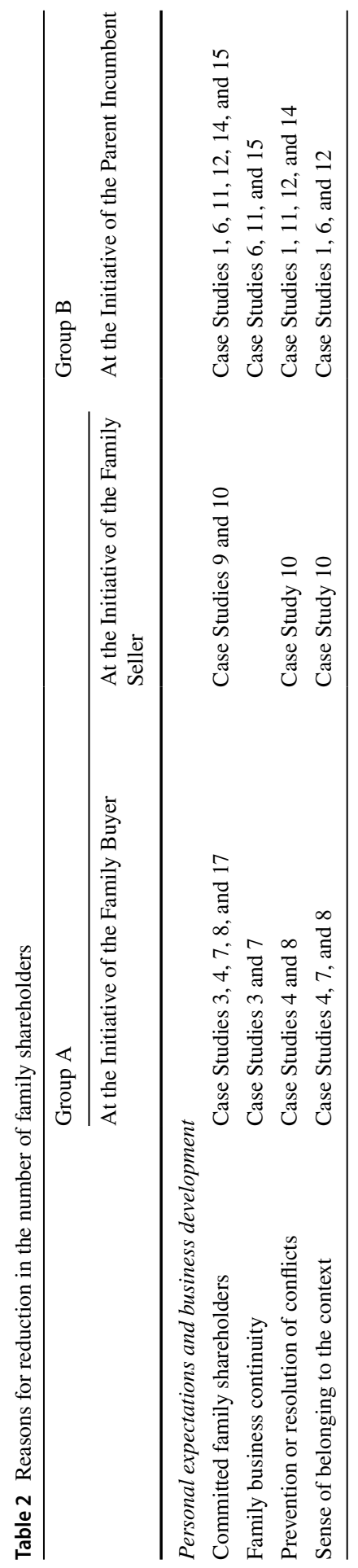


Especially within Group A, the consultants' work was not straightforward because the incumbent owners were reluctant to accept the proposed evaluation as it was always considered "below the immeasurable value represented by our long family tradition" and from complexity derived from the "goal of conferring different shares among successors to recognize the true efforts of each of them, trying to separate family from business." (Case 14).

Within Group B, the process of selling and purchasing shares among family members took place without significant problems due to the clear desire to either retain or transfer the property.

Consequences. As in the original study, both Group A and Group B reported positive effects after ownership pruning, as shown in the following statements:

After the acquisition, the company's performance improved, probably because all of the discussions and recriminations directed toward those who showed less interest have ended. Now we make better use of the time available, and the results are visible. (Case 10)

I can safely say that the company has grown since we have better defined the ownership shares. Taking responsibility has made us more attentive and even more committed to the company's survival and success over time. (Case 1)

In addition, in the cases used in this replication study we find that ownership pruning generally enhanced family relationships, except in Cases 4 and 14, where simplifying the business ownership caused family conflicts.

\subsection{Simplifying the ownership structure by splitting the family business}

Why? The original study of Lambrecht and Lievens (2008) identified splitting as another way to prune the family shareholding tree. This was carried out in Cases 13 and 16. The main reason was the need to solve conflicts among successors after the predecessors exit, as follows:

When my father and my uncle decided to pass the firm to my cousins and us, the problems started. Their exit from the company and our complete takeover would undoubtedly have led to closing the family business that has lasted for 130 years. So, we decided to split up. (Case 13)

We decided to split to ensure the firm's growth after succession. The glue was our father; when the firm was passed to us, conflicts started. Splitting was the right choice. (Case 16)

How? As in the original study, splitting involved a long and emotionally tricky operation, as shown here:

The split lasted two years. It involved us all, especially emotionally. (...) their business [referred to father and uncle] has survived the darkest periods of history and we, their descendants, were the cause of its division. (Case 13)

My father and my uncle founded our family business. Initially, me and my cousins' entry was simple. However, when we started planning the genera- 
tional transition, the problems started. (...) none of us accepted the others' proposals. The split was the only way out. (Case 16)

Despite emotional concerns, splitting can be the best way to assure the firm's continuity. Unlike businesses in the original study that split up, the process described by the participants in these case studies was not peaceful, but thanks to external financial, fiscal, and legal support it was completed. Outside expertise was necessary due to the technical aspects of a split. Exemplifying, in Case 16, the intervention of the professionals was crucial above all as regards decisions on which business segment to assume and which employees incorporate in the new business: "(..) the decision which branch to attribute to each of us generated strong conflicts, as well as when we had to choose which of the employees to give to the different companies. Above all our old employees did not believe what was happening. It seemed like a drawing of lots. Fortunately, we relied on experts who helped us react more rationally, leading us to reflect for the firm's good and not for our interests.". Moreover, these outsiders can provide rational input and help to mediate conflicts, becoming "the third voice able to create equilibrium and assuming a more rational behavior." (Case 13).

Consequences. As in the original study, our results show that splitting creates a more streamlined business structure that often improves family dynamics; in particular, it prevents the onset of conflicts that could lead to problems that may threaten the firm's survival, as narrated by this interviewee:

Our parents have suffered a lot because they have always been very close to each other and seeing us so far away doesn't have to be a pleasant thing. Today, however, we can say that it was a wise decision and, before COVID-19, the business was booming. (Case 13)

In Case Study 13, splitting "has solved many conflicts and enhanced the business" and in Case 16 it led to improved profits in both of the businesses after the split. Each independent firm now reflects the traditions and heritage of the original family enterprise. In Case 13, family members cited the potential consequences of not splitting by emphasizing that the family business would no longer exist had it not been for the split.

However, the main benefits to a family from splitting up a business are that doing so prevents fractures within the family, creates more straightforward family governance structures, and offers family members the possibility of becoming more deeply engaged to achieve personal ambitions.

In contrast to findings in Lambrecht and Lievens (2008), we find that family owners are worried about context legitimization, as shown in the following statements:

Everyone has always known the united enterprise and has experienced collaboration between my father and my uncle. The split was a courageous decision also from that point of view, because we feared losing the reputation we have always had in our context. (Case 13)

It was not easy for us to be accepted as two new companies. (...) I do not deny that our territory's response was initially not the best, but over time things have settled down. (Case 16) 


\subsection{Simplicity and governance}

We found almost no formalized governance structures in our case studies because the firms are small, and "a formal structure could compromise timeliness in making decisions and loosen family control over the company" (Case 4). Family owners "do not feel the need for formalisms" because they maintain that their strengths are "flexibility and timeliness" (Case 1). Only Case 16 introduced changes in the business's governance structure.

Why? Varying from the original study, the family business in Case 16 simplified its governance structure, changing from a board of directors to an advisory board because "making decisions was becoming exhausting: the discussions were endless, and instead of thinking as members of the same team, we were thinking as opponents."

How? In Case 16, simplifying means involving experts who make suggestions and offer "inspiring ideas and strategies." The decision-making power, though, remains in the hands of family members, as follows:

After the de-merger, we set up an advisory board with the specific intent of listening to their suggestions without them being binding. We are free to decide with more serenity. (Case 16)

Consequences. In line with the original study, Case 16 shows that a simpler governance structure "(...) allows us to avoid wasting time on useless discussions so that we can concentrate our energies on the validity of proposals and not on who submitted them." This highlights that simpler the governance improves the timeliness of decisions.

\subsection{Simplifying management structure by reducing the number of family managers}

Why? Similar to Lambrecht and Lievens (2008), we find that firms that simplified their management structure (Cases $8,9,11$, and 12) generally did so while simultaneously pruning the ownership structure. The main reasons are primarily due to the need to confer decision-making power only to those actively engaged in the company, and to define a specific order within the company, distributing tasks more effectively and efficiently to avoid the old Sardinian saying, "one hundred heads, one hundred hairs."1

Regarding the first motivation, examples can be seen in the following statements:

We have drastically reduced the number of owners and the number of who can decide. (...) My two sisters, who have never really committed themselves to

\footnotetext{
${ }^{1}$ The Sardinian saying "centu concas, centu berrittas," translates to "one hundred heads, one hundred hairs." It is one of the most common proverbs in Sardinia and can be interpreted as being either negative or positive. It can mean that Sardinians are not united, or it can mean that every Sardinian has the ability to think independently, without restrictions.
} 
the family business, were then expelled both from ownership and from management. (Case 8)

(...) There were eight of us, including my father. Our father took a courageous stance during the generational shift and decided, looking into our eyes, to prune the company's ownership and management drastically. Now I am the sole owner and sole manager, and the others play different roles. (Case 11)

In the second case, the following quote clarifies the reason for simplifying:

Why was there only me left, out of so many of us? Do you know the saying, “centu concas, centu berrittas?" Here ... too many different opinions and little concord. (...) But above all, too much difference in the level of personal commitment to our company. (Case 12)

Only in Cases 2 and 5 did management pruning happen independently of ownership pruning, because the firm is considered a family asset. Therefore, it is considered appropriate for the ownership to be spread among several family members who are higher in the family hierarchy than those who are officially in charge of making decisions for the business. The following statement clarifies this:

(...) I have the last word on important decisions, but the ownership is shared, albeit in different numbers of shares, between my brothers and me. (Case 2)

How? All of the firms that pruned management designated one family to be the executive manager, allocating the others to different roles with "diverse decisionmaking powers and responsibilities" (Case 2). The designations were made by "facing and solving conflicts among successors" (Case 12) and "sharing the decision in harmony" (Case 9).

Consequences. Management pruning "has enhanced firm performance, increased speed in making decisions, and given an innovative boost to the firm" (Case 14), and has had a positive impact on family harmony:

Now everything is simpler, and paradoxically our family relationships are also much more relaxed and harmonious. We probably should have made this decision even earlier. (Case 12)

\subsection{Discussion}

Lambrecht and Lievens (2008) found that pruning the family tree promptly offers a promising path to family harmony and improved business performance. In sum, our findings confirm theirs, with some exceptions and extensions. Concerning the what, our findings agree with the original study by underlining that family tree pruning means a reduction in the number of family owners and/or family managers. However, our results also differ from those in the original study and partially agree with Lansberg's (1999) devolutionary succession model, because pruning in our case studies occurred both intragenerationally and intergenerationally. Specifically, Cases $1,2,5,6,11,12,13,14$, and 15 experienced pruning during a generational shift due to the incumbent owners' desire to avoid potential conflicts among their 
successors. Cases 3, 4, 7, 8, 9, 10, 16, and 17 experienced pruning after the baton was passed. Confirming Lambrecht and Lievens (2008), our findings show that simplifying the shareholding structure generally involves reducing the number of family shareholders, except in Cases 13 and 16, which split their family businesses into two independent firms. Extending the original study, our findings provide evidence that pruning often includes excluding passive family members from ownership or senior management positions. This extends previous studies (Cassidy and McGrath 2014; Matser et al. 2020; Van der Meulen et al. 2015) that maintained successful succession can result from unequal treatment of successors defined by an uneven distribution of ownership shares among them. In Sardinian culture, distributing a family inheritance unequally is a custom with ancient roots. In fact, although each successor may receive the same share of the family patrimony, this can happen in different ways and at different times. Even now, successors receive what they need when the need arises, subsequently renouncing a pro-rata distribution of the remaining part of the family assets. This behavior can be seen in the case studies analyzed, in which individuals who were excluded from having an ownership share were given different roles within the firm. Our findings show that simplicity translates into flexibility and more timeliness in decision-making, as well as the possibility of reducing relational difficulties. Above all, simplicity consists of bestowing the power and responsibility for defining the development of the family business only upon those who are truly committed to and engaged in the business.

Concerning the why question, consistent with Lambrecht and Lievens (2008) our case studies identify the main reasons for pruning as the desire to achieve growth and survival for the firm across generations and to better manage family intragenerational and intergenerational conflicts. However, we also find another reason: a strong dependence on the context that results in a strong sense of identity and identification with the territory and serves as a means of selecting between active and passive family owners. Active owners appear to be interested in managing the firm for themselves, and as a way to ascribe validity local traditions and obtain legitimacy from the context in which they live and operate. Passive family owners appear less engaged than their counterparts, and do not perceive themselves as having a mission to preserve, protect, and hand down knowledge, skills, and centuries-old traditions embedded in the family business to future generations. Furthermore, the original study found that simplifying the ownership structure occurs due to willingness on the part of both family buyers and family sellers. Extending this result, our findings shed new light on incumbent/parent roles as active actors who are able to see that ownership pruning before leaving the firm can prevent conflicts among their offspring.

Focusing on the how question and the consequences of pruning, our results confirm the findings in the original study, highlighting the importance of involving experts and business consultants to define the economic value of the business. The role of experts was also critical during debates between family members, helping to direct decision-making more rationally, shifting attention from the subjective (who proposed the suggestion) to the objective (what is suggested). In other words, the experts also facilitated communication and acted as mediators in family business relationships. 
Concerning ownership pruning via splitting, our findings reinforce Lambrecht and Lievens (2008) by identifying the split as a useful means of simplifying the family tree ownership structure and ensuring a family firm's survival when conflicts impair family relationships. Moreover, by extending the original results, we show the respondents' concerns with respect to legitimacy conveyed by the context due to long-term relationships with local actors built by the family over time.

Regarding simplicity in governance, our findings confirm those of Lambrecht and Lievens (2008), except that the firms in our case studies, which are exclusively small and medium sized firms, do not perceive the need to formalize a well-defined governance structure that could reduce the timeliness of decision-making and, more importantly, could even loosen the family's control over the company. Concerning simplicity in the management structure, our findings align with the original study which states that simplifying the management structure when ownership pruning occurs allocates decision-making power only to family owners who are engaged and committed, and defines tasks and roles more effectively.

\section{Conclusion}

This study, which aims to replicate the work in Lambrecht and Lievens (2008), contributes to the discussion about the relevance of managing the complexity of family firms to support firms' performance and longevity while promoting family harmony by reducing the number of family owners and/or managers, an understudied topic in literature. In fact, although several studies have debated the risks of dispersing the family's property and addressed discrepancies in the objectives of active and passive owners as a possible cause of family relation ruptures and threats to family harmony (Basco 2013; Blanco-Mazagatos et al. 2016; Calabrò et al. 2017; Campopiano et al. 2020a, b; De Massis et al. 2013; Eddleston et al. 2008; Hoskisson et al. 2017; Sandig et al. 2006), we found no recent studies that follow Lambrecht and Lievens's (2008) intuition regarding the role of pruning.

This replication largely confirms the validity of the original study's results, particularly with respect to the relevance of pruning with respect to increasing firm performance and ensuring firm survival through family harmony. Our findings also extend the original results and offer interesting academic and practical implications.

\subsection{Scholarly contributions}

Our results contribute to family business literature in at least three ways.

First, the most novel finding resulting from the replication is that pruning frequently takes place during a generational shift. This leads to more rational successions that are less characterized by the emotional aspects that usually affect this crucial moment in the lifecycle of a family business. Pruning makes it possible to manage current conflicts and prevent future ones after the incumbent's exit and is, therefore, a useful tool in achieving a successful generational transition. In particular, our findings introduce the role of the incumbent, which appears to be decisive in 
choosing the successor(s), who must possess certain skills, abilities, and aptitudes. Through pruning, the incumbent defines the shares, roles, and business relationships between the different successors, with the goal of ensuring that the firm is entrusted to those who are committed to continuing its success, and have shown a particular attachment to and a strong sense of the firm's identity. Our replication has shown that predecessors exhibit courage in taking a strong position to identify the most suitable successor or successors to promote the company's longevity across generations. This aspect is fascinating because it highlights the importance of the incumbent's clarity and objectivity in managing the emotional aspects of a generational transition. In this sense, pruning during succession appears a suitable way to avoid what Bertrand et al. (2008) highlight, that is the "race to the bottom" wherein, after the founder's death, each brother attempts to gain resources before the other brothers can do so. Moreover, our results extend Gagné et al. (2021) and De Massis et al. (2008) 's findings by introducing the rational decision of pruning on the incumbent side as a practical and effective tool to leverage on successor(s) 's burden of responsibility and motivation and ensure the firm longevity.

Second, our findings show that pruning the family tree helps manage intragenerational and intergenerational conflicts. Previous studies have found that perceived injustice produces negative emotions that trigger conflict, especially between siblings, and during critical events such as ownership transfer, succession, and pay dispersion (Avloniti et al, 2014; Ensley et al, 2007). Our study, in line with Picone et al. (2021) and Humphrey et al. (2021), highlights that managing emotions is a driver to ensure family firm's success, and pruning appears to be a helpful tool to manage emotions, and conflicts between family members, mainly when derived from conflicts of interest between active and passive siblings and/or family members.

Third, our study follows previous researches that have underlined the relevance of investigating family businesses under the environmental contexts' lens to contribute to the family firm heterogeneity studies (Daspit et al. 2021). Our findings stress the importance of context as a variable that influences a family firm's strategies and behavior, especially concerning the motivations for pruning and the role played by the incumbent. From the interviews conducted, the feeling of identity and identification with the territory and the importance of adhering to local traditions and culture emerged as an essential element affecting the choice of potential owners in the next generation, especially for those small and medium firms that draw their lifeblood from the territory and its traditions, and particularly from legitimacy granted by local stakeholders who greatly influence the success or failure of a small business. This reputation in the local context has a substantial effect on the company's survival during and after a generational change. The sense of attachment to a context can stimulate or inhibit the will of successors to continue the family firm, particularly when the firm is deeply embedded in a social network that affects its strategies and behaviors or when it operates in a traditional industry. 


\subsection{Implications for practitioners}

Family firms and consultants who work with them should consider that simplifying by pruning can be an effective path to family harmony and better business performance. Over generations, family businesses inevitably face growing ownership complexity. This can have adverse effects on the family and the business, which can be substantially reduced via pruning. Incumbents could be inspired to face succession by making courageous decisions and can improve outcomes by thinking of family and the business as separate entities to identify the right successor(s), without concern for kinship ties which, on the contrary, tend to improve through pruning. This replication demonstrates that conflicts often occur precisely because of to grant equal authority to all family members that tends to generate misunderstandings and foster ill will among siblings. These results can inspire parents to involve business consultants and other experts in the pruning process to provide an objective view of the generational transition, to help with the valuation of the firm, and act as moderators in family business communication.

Finally, our findings are particularly useful for practitioners involved in succession planning to decide how best to help family businesses overcome succession challenges. Consultants must acquire mediation skills between opposing interests in succession processes to facilitate communication between family members, especially between incumbents and successors when the former intends to confer most or all of the ownership shares on a single successor or to specific successors who have previously distinguished themselves in terms of their skills, commitment to the business, and willingness to pursue the entrepreneurial initiative with determination.

We know that pruning can generate different effects, depending on many aspects. For example, the firm's small size may not guarantee a good future for all successors, so pruning is more related to the need to take place outside the family business than a deliberate choice. Children's career prospects, which often differ from parents' expectations, could also induce uninterested successors to liquidate their shares. In this case, pruning would take place peacefully and consensually. On the other hand, if several successors show will and desire to continue the family business and the incumbent decides to identify the successor and exclude the others, the pruning would create undoubted adverse effects due to the spread of negative emotions dictated by the perception of injustice and damage received. In sum, although our study has shown that pruning has generated positive effects in the cases analyzed, it is not possible to state a priori that this can happen in all cases: it depends on the different characteristics of the family businesses examined, due to the marked heterogeneity that characterizes them.

\subsection{Limitations and further research}

Although the goal of our study was to replicate the original study as closely as possible, some extensions in our sample might have influenced the results and their applicability. Our case studies involved one respondent, the knowledgeable agent, for each family firm, which might have influenced the results. Therefore, further studies 
should investigate the pruning phenomenon using a multi-respondent approach. Furthermore, as it became clear that context plays an essential role in the analysis, further studies could use a cross-cultural approach. Finally, pruning effects could be evaluated in longitudinal studies to understand whether and how subsequent generations repeat the pruning process.

\section{Declarations}

Conflict of interest We have not received funding for this study and there are no conflicts of interest to declare.

\section{References}

Anderson RC, Duru A, Reeb DM (2009) Founders, heirs, and corporate opacity in the United States. J Financ Econ 92:205-222. https://doi.org/10.1016/j.jfineco.2008.04.006

Astrachan JH, Shanker MC (2003) Family businesses' contribution to the U.S. economy: a closer look. Fam Bus Rev 16:211-219. https://doi.org/10.1177/08944865030160030601

Avloniti A, Iatridou A, Kaloupsis I, Vozikis GS (2014) Sibling rivalry: implications for the family business succession process. Int Entr Man J 10:661-678. https://doi.org/10.1007/s11365-013-0271-6

Barontini R, Bozzi S (2018) Family firm heterogeneity and CEO compensation in Continental Europe. J Econ Bus 97:1-18. https://doi.org/10.1016/j.jeconbus.2018.02.001

Basco R (2013) The family's effect on family firm performance: a model testing the demographic and essence approaches. J Fam Bus Strategy 4:42-66. https://doi.org/10.1016/j.jfbs.2012.12.003

Baù M, Chirico F, Pittino D, Backman M, Klaesson J (2019) Roots to grow: family firms and local embeddedness in rural and urban contexts. Entrep Theor Pract 43:360-385. https://doi.org/10.1177/ 1042258718796089

Bergh DD, Sharp BM, Aguinis H, Li M (2017) Is there a credibility crisis in strategic management research? Evidence on the reproducibility of study findings. Strateg Organ 15:423-436. https://doi. org/10.1177/1476127017701076

Bertrand C, Bourdeau L (2010) Research interviews by Skype: a new data collection method. Paper Presented at the Proceedings of the 9th European Conference on Research Methodology for Business and Management Studies, Madrid, Spain

Bertrand M, Johnson S, Samphantharak K, Schoar A (2008) Mixing family with business: a study of Thai business groups and the families behind them. J Financ Econ 88:466-498. https://doi.org/10.1016/j. jfineco.2008.04.002

Bettis RA, Helfat CE, Shaver JM (2016) The necessity, logic, and forms of replication. Strateg Manag J 37:2193-2203. https://doi.org/10.1002/smj.2580

Blanco-Mazagatos V, de Quevedo-Puente E, Delgado-García JB (2016) How agency conflict between family managers and family owners affects performance in wholly family-owned firms: a generational perspective. J Fam Bus Strategy 7:167-177. https://doi.org/10.1016/j.jfbs.2016.07.003

Block JH, Kuckertz A (2018) Seven principles of effective replication studies: strengthening the evidence base of management research. Manag Rev Q 68:355-359. https://doi.org/10.1007/ s11301-018-0149-3

Brumana M, Minola T, Garrett RP, Digan SP (2017) How do family firms launch new businesses? A developmental perspective on internal corporate venturing in family business. J Small Bus Manag 55:594-613. https://doi.org/10.1111/jsbm.12344

Calabrò A, Campopiano G, Basco R (2017) Principal-principal conflicts and family firm growth: the moderating role of business family identity. J Fam Bus Manag 7:291-308. https://doi.org/10.1108/ JFBM-02-2017-0005

Campopiano G, Brumana M, Minola T, Cassia L (2020a) Does growth represent chimera or Bellerophon for a family business? The role of Entrepreneurial orientation and family influence nuances. Eur Manag Rev 17:765-783. https://doi.org/10.1111/emre.12351 
Campopiano G, Calabrò A, Basco R (2020b) The "most wanted": the role of family strategic resources and family involvement in CEO succession intention. Fam Bus Rev 33:284-309. https://doi.org/10. $1177 / 0894486520927289$

Caputo A, Marzi G, Pellegrini MM, Rialti R (2018) Conflict management in family businesses: a bibliometric analysis and systematic literature review. IJCMA 29:519-542. https://doi.org/10.1108/ IJCMA-02-2018-0027

Carney M (2005) Corporate governance and competitive advantage in family-controlled firms. Entrep Theor Pract 29:249-265. https://doi.org/10.1111/j.1540-6520.2005.00081.x

Carney M, Gedajlovic E (2002) The coupling of ownership and control and the allocation of financial resources: evidence from Hong Kong. J Manag Stud 39:123-146. https://doi.org/10.1111/14676486.00285

Cassidy A, McGrath B (2014) The relationship between "Non-successor" farm offspring and the continuity of the irish family farm. Soc Ruralis 54:399-416. https://doi.org/10.1111/soru.12054

Chen L, Zhu JA, Fang H (2021) The rise of family business in China before 1949. In: Family business in China, 1. Springer, pp 99-131

Colli A (2012) Contextualizing performances of family firms: the perspective of business history. Fam Bus Rev 25:243-257. https://doi.org/10.1177/0894486511426872

Crenos (2020) Economia della sardegna. $27^{\circ}$ rapporto. Arcadia

Daspit JJ, Chrisman JJ, Ashton T, Evangelopoulos N (2021) Family Firm Heterogeneity: a definition, common themes, scholarly progress, and directions forward. Fam Bus Rev 34:296-322. https://doi. org/10.1177/08944865211008350

Davis JA (2008) Toward a typology of family business systems. In: Family values and value creation. Palgrave Macmillan, London, pp 127-154

De Massis A, Chua JH, Chrisman JJ (2008) Factors preventing intra-family succession. Fam Bus Rev 21(2):183-199. https://doi.org/10.1111/j.1741-6248.2008.00118.x

De Massis A, Kotlar J, Campopiano G, Cassia L (2013) Dispersion of family ownership and the performance of small-to-medium size private family firms. J Fam Bus Strategy 4:166-175. https://doi.org/ 10.1016/j.jfbs.2013.05.001

Deakin H, Wakefield K (2014) Skype interviewing: reflections of two PhD researchers. Qual Res 14:603616. https://doi.org/10.1177/1468794113488126

Dettori A, Floris M, Dessì C (2020) Customer-perceived quality, innovation and tradition: some empirical evidence. TQM J32:1467-1486. https://doi.org/10.1108/TQM-11-2019-0273

Eddleston KA, Otondo RF, Kellermanns FW (2008) Conflict, participative decision-making, and generational ownership dispersion: a multilevel analysis. J Small Bus Manag 46:456-484. https://doi.org/ 10.1111/j.1540-627X.2008.00252.x

Eisenhardt KM (1989) Building theories from case study research. Acad Manag Rev 14:532-550. https:// doi.org/10.5465/amr.1989.4308385

Eisenhardt KM, Graebner ME (2007) Theory building from cases: opportunities and challenges. Acad Manag J 50:25-32. https://doi.org/10.5465/amj.2007.24160888

Ensley MD, Pearson AW, Sardeshmukh SR (2007) The negative consequences of pay dispersion in family and non-family top management teams: an exploratory analysis of new venture, high-growth firms. J Bus Res 60:1039-1047. https://doi.org/10.1016/j.jbusres.2006.12.012

EU (2020) Unleashing the full potential of European SMEs. https://ec.europa.eu/commission/presscorner/detail/en/fs_20_426

EY (2017) Family business yearbook. https://familybusiness.ey-vx.com/fb-yearbook-flipbook-2017/ mobile/index.html\#p=1

Fitz-Koch S, Nordqvist M (2017) The reciprocal relationship of innovation capabilities and socioemotional wealth in a family firm. J Small Bus Manag 55:547-570. https://doi.org/10.1111/jsbm.12343

Floris M, Dettori A, Dessì C (2020) Innovation within tradition: interesting insights from two small family bakeries. Piccola Impresa/Small Bus 1

Gagné M, Marwick C, Brun de Pontet S, Wrosch C (2021) Family business succession: What's motivation got to do with it? Fam Bus Rev 34:154-167. https://doi.org/10.1177/0894486519894759

Gersick KE, Davis JA, McCollom Hampton M, Lansberg IS (1997) Generation to generation: life cycles of the family business. Harvard Business School Press

Gibb Dyer WG (2006) Examining the "family effect" on firm performance. Fam Bus Rev 19:253-273. https://doi.org/10.1111/j.1741-6248.2006.00074.x

Gimeno A, Baulenas G, Coma-Cros J (2010) Family business models. In: Family business models. Palgrave Macmillan, London, pp 57-77 
Gioia DA, Corley KG, Hamilton AL (2013) Seeking qualitative rigor in inductive research: notes on the Gioia methodology. Organ Res Methods 16:15-31. https://doi.org/10.1177/1094428112452151

González-Cruz TF, Cruz-Ros S (2016) When does family involvement produce superior performance in SME family business? J Bus Res 69:1452-1457. https://doi.org/10.1016/j.jbusres.2015.10.124

Großmann S, Von Schlippe AV (2015) Family businesses: fertile environments for conflict. J Fam Bus Manag 5:294-314. https://doi.org/10.1108/JFBM-11-2014-0038

Gubitta P, Gianecchini M (2002) Governance and flexibility in family-owned SMEs. Fam Bus Rev 15:277-297. https://doi.org/10.1111/j.1741-6248.2002.00277.x

Habbershon TG, Williams ML, MacMillan IC (2003) A unified systems theory of family firm performance. J Bus Res 18:451-465

Hoskisson RE, Chirico F, Gambeta ZJ, E, (2017) Managerial risk taking: a multitheoretical review and future research agenda. J Manag 43:137-169. https://doi.org/10.1177/0149206316671583

Humphrey RH, Massis AD, Picone PM, Tang Y, Piccolo RF (2021) The psychological foundations of management in family firms: emotions, memories, and experiences. Fam Bus Rev 34:122-131. https://doi.org/10.1177/08944865211012139

Iacono VL, Symonds P, Brown DH (2016) Skype as a tool for qualitative research interviews. Soc Res Online 21:1-9

Kammerlander N, Dessì C, Bird M, Floris M, Murru A (2015) The impact of shared stories on family firm innovation a multicase study. Fam Bus Rev 28:332-354. https://doi.org/10.1177/0894486515 607777

Kellermanns FW, Eddleston KA (2004) Feuding families: when conflict does a family firm good. Entrep Theor Pract 28:209-228. https://doi.org/10.1111/j.1540-6520.2004.00040.x

Klein PG, Mahoney JT, McGahan AM, Pitelis CN (2010) Toward a theory of public entrepreneurship. Eur Manag Rev 7:1-15. https://doi.org/10.1057/emr.2010.1

Kotlar J, De Massis A (2013) Goal setting in family firms: goal diversity, social interactions, and collective commitment to family-centered goals. Entrep Theor Pract 37:1263-1288. https://doi.org/10. 1111/etap. 12065

Labaki R (2007) Contribution à la connaissance des liens familiaux dans les entreprises familiales françaises cotées: renforcement versus atténuation. Bordeaux

Lambrecht J, Lievens J (2008) Pruning the family tree: an unexplored path to family business continuity and family harmony. Fam Bus Rev 21:295-313. https://doi.org/10.1177/08944865080210040103

Lansberg IS (1999) Succeeding generations. Harvard Business School Press. http://www.netlibrary.com/ urlapi.asp? action $=$ summary $\& v=1 \&$ bookid $=35047$

Martin-Cruz N, Barros Contreras I, Hernangómez Barahona J, Pérez Fernández H (2020) Parents' learning mechanisms for family firm succession: an empirical analysis in Spain through the lens of the dynamic capabilities approach. Sustainability 12:8220. https://doi.org/10.3390/su12198220

Matser I, Bouma J, Veldhuizen E (2020) No hard feelings? Non-succeeding siblings and their perceptions of justice in family firms. J Fam Bus Manag 6:66. https://doi.org/10.1108/JFBM-09-2018-0048

Memili E, Chang EPC, Kellermanns FW, Welsh DHB (2015) Role conflicts of family members in family firms. Eur J Work Organ Psychol 24:143-151. https://doi.org/10.1080/1359432X.2013.839549

Miller D, Le Breton-Miller I (2006) Family governance and firm performance: agency, stewardship, and capabilities. Fam Bus Rev 19:73-87. https://doi.org/10.1111/j.1741-6248.2006.00063.x

Montemerlo D (2005) Family ownership: boost or obstacle to growth. FBN-IFERA World Academic Research Forum, EHSAL Brussels

Mukherjee K, Rautiainen M, Pihkala T, Rosa P (2019) The dynamics and complexity of family business groups. In: The family Business Group Phenomenon. Springer, pp 177-200

Nordqvist M, Sharma P, Chirico F (2014) Family firm heterogeneity and governance: a configuration approach. J Small Bus Man 52:192-209. https://doi.org/10.1111/jsbm.12096

OECD P (2017) Enhancing the contributions of SMEs in a global and digitalised economy. Paris. Accessed 25 Feb2019

Oudah M, Jabeen F, Dixon C (2018) Determinants linked to family business sustainability in the UAE: an AHP approach. Sustainability 10:246. https://doi.org/10.3390/su10010246

Picone PM, De Massis A, Tang Y, Piccolo RF (2021) The psychological foundations of management in family firms: Values, biases, and heuristics. Fam Bus Rev 34:12-32. https://doi.org/10.1177/08944 86520985630

Qiu H, Freel M (2020) Managing family-related conflicts in family businesses: a review and research agenda. Fam Bus Rev 33:90-113. https://doi.org/10.1177/0894486519893223 
Sandig AG, Labadie GJ, Saris W, Mayordomo XM (2006) Internal factors of family business performance: an integrated theoretical model. In: Handbook of research in family business, pp 145-164

Santulli R, Torchia M, Calabrò A, Gallucci C (2019) Family ownership concentration and firm internationalization: integrating principal-principal and socioemotional wealth perspectives. J Int Entrep 17:220-248. https://doi.org/10.1007/s10843-019-00245-4

Schulze WS, Lubatkin MH, Dino RN (2003) Exploring the agency consequences of ownership dispersion among the directors of private family firms. Acad Manag J 46:179-194

Schwass J (2005) Wise growth strategies in leading family businesses. Springer

Sharma P, Manikutty S (2003) Shedding of unproductive resources in family firms: role of family structure and community culture. The School of Business and Economics publishes working papers

Sharma P, Nordqvist M (2013) Using the configuration approach to understand the reasons for and consequences of varied family involvement in business. In: Handbook of research on family business, 2nd edn. Edward Elgar

Shepherd DA, Zacharakis A (2000) Structuring family business succession: an analysis of the future leader's decision making. Entrep Theor Pract 24:25-39. https://doi.org/10.1177/104225870002400402

Siebels JF, zu Knyphausen-Aufseß D (2012) A review of theory in family business research: the implications for corporate governance. Int J Manag Rev 14:280-304. https://doi.org/10.1111/j.1468-2370. 2011.00317.x

Simon A, Marquès P, Bikfalvi A, Dolors Muñoz MD (2012) Exploring value differences across family firms: the influence of choosing and managing complexity. J Fam Bus Strategy 3:132-146. https:// doi.org/10.1016/j.jfbs.2012.05.003

Singh K, Ang SH, Leong SM (2003) Increasing replication for knowledge accumulation in strategy research. J Manag 29:533-549. https://doi.org/10.1016/S0149-2063(03)00024-2

Suáre KC, Santana-Martín DJ (2004) Governance in Spanish family business. Int J Entrep Behav Res 10:141-163. https://doi.org/10.1108/13552550410521425

Toncar MF, Munch JM (2010) Meaningful replication: when is a replication no longer a replication? A rejoinder to Stella and Adam (2008). J Mark Theor Pract 18:71-80. https://doi.org/10.2753/MTP10 69-6679180105

Van der Meulen H, Terluin I, Matser I (2015) The role of women on Dutch farms. In: 20th International farm manage congress. Laval University, Québec City, QC, Canada

Weismeier-Sammer D (2011) Entrepreneurial behavior in family firms: a replication study. J Fam Bus Strategy 2:128-138. https://doi.org/10.1016/j.jfbs.2011.07.003

Westhead P, Howorth C, Cowling M (2002) Ownership and management issues in first generation and multi-generation family firms. Entrep Reg Dev 14:247-269. https://doi.org/10.1080/0898562011 0112088

Witt P (2008) Corporate Governance in Familienunternehmen. Z Betriebswirtschaft 78:1-19

Yin RK (2008) Case study research, 4th ed. Sage

Zahra SA, Wright M, Abdelgawad SG (2014) Contextualization and the advancement of entrepreneurship research. Int Small Bus J 32:479-500. https://doi.org/10.1177/0266242613519807

Publisher's Note Springer Nature remains neutral with regard to jurisdictional claims in published maps and institutional affiliations. 